\title{
ENTRE DUAS PREGUIÇAS: MACUNAÍMA E O JECA TATU
}

\author{
Pedro Meira Monteiro*
}

Resumo: Entre Jeca Tatu, o caboclo "inadaptável à civilização", e o matuto solerte e imprevisível que é Macunaíma, estende-se o largo espectro das discussões sobre o homem e a terra, que marcaram tão fundo a imaginação social e literária brasileira. Este artigo pretende averiguar como, em diferentes figurações da "preguiça", em Monteiro Lobato e Mário de Andrade, projetam-se seus desejos, seus temores e suas interrogações sobre o futuro do Brasil.

Palavras-chave: Civilização e preguiça; Monteiro Lobato; Mário de Andrade.

Abstract: Between Jeca Tatu, the caboclo "unadaptable to civilization", and Macunaíma, the ingenious and impredictable matuto, one can find the large spectrum of the debates on man and earth, which left a deep mark on the social and literary imagination of Brazil. This article aims at suggesting how, in different representations of lazyness in Monteiro Lobato and Mário de Andrade, one can perceive their own desires and fears, as well as their inquiries into the future of Brazil.

Keywords: Civilization and Lazyness; Monteiro Lobato; Mário de Andrade.

\footnotetext{
* Graduado em Ciências Sociais pela Unicamp, tem um D. E. A. em História Sócio-Cultural pela Université de Versailles Saint-Quentin-en-Yvelines. É Mestre em Sociologia e Doutor em Teoria e História Literária, ambos pela Unicamp. Atualmente é Professor titular no Departament of Spanish and Portuguese Languages and Cultures, Princeton University. E-mail: pmeira@princeton.edu.

${ }^{1}$ Este artigo é uma versão bastante retrabalhada da apresentação que fiz na quinta conferência da APSA (American Portuguese Studies Association), na Universidade de Minnesota, em outubro de 2006, num painel sobre Monteiro Lobato organizado por Malcolm McNee. Agradeço a ele, bem como a Marisa Lajolo, pelo diálogo e pelas observações então feitas.
} 
$\mid 66$ |

Entre duas preguiças: Macunaíma e o Jeca Tatu

No contraste entre Monteiro Lobato (1882-1948) e Mário de Andrade (1893-1945), e entre dois de seus personagens mais famosos - Jeca Tatu e Macunaíma -, há diferenças notáveis que, bem analisadas, permitem compreender o sentido de suas apostas sobre o que poderia vir a ser o Brasil.

Ressalvadas as singularidades, os dois autores viam, na produção literária, verdadeira missão, espécie de entrega do sujeito à verdade do destino coletivo. É claro que o tamanho de tal missão há muito nos escapa, talvez porque o caráter demiúrgico da função intelectual tenha se esgotado, ou talvez porque nosso tempo já não nos permita os arroubos de uma imaginação que tinha, por tarefa, dar conta de nada menos que o Brasil inteiro.

Embora o Monteiro Lobato que aqui apareça, contraposto a Mário de Andrade, seja autor de uma literatura para adultos, seria empobrecedor esquecer-se da importância que ele teve como autor também da mais poderosa literatura infantil. Não é exagerado supor que, no horizonte médio de um leitor no Brasil, o Sítio do Picapau Amarelo pôde ocupar aquele espaço mítico da aventura formadora, como são as planícies do Mississippi no Huckleberry Finn, para os leitores norte-americanos, e como terão sido as pradarias do Oeste americano e o Curdistão bravio, para os leitores de Karl May, dentro e fora da Alemanha. Trata-se daquilo que, pensando na formação de leitores, Lêdo Ivo (1982) chamou de "ética da aventura": uma conjunção de valores fundamentais hauridos nos livros infanto-juvenis, que ele referia sobretudo às aventuras no mar. Trata-se ainda da experimentação que, transmitida ao leitor, conforma o "direito de inventar, desinventar e transformar a linguagem", na sugestão de Marisa Lajolo (2008, p. 21-22) a respeito de Lobato, quando nota que, nas fábulas do Sítio, uma sofisticada reflexão metalinguística ganha "dicção calibrada para o público infantil".

Parto da lembrança da literatura infantil para chamar atenção sobre o estatuto formador da produção literária de Lobato, mais precisamente o aspecto pedagógico de sua impressionante atividade como homem de cultura - editor, em particular, e agitador, em tantos âmbitos e sentidos. Há algo incansável em 
sua biografia, sentimento que talvez ajude a compreender as razões pelas quais sua pena combate as sementes do atraso, ou, na voga do tempo, aquilo que seria identificado a um mal de formação.

As metáforas orgânicas são importantes, não apenas por atualizar a concepção do avanço político como evolução - o que certamente pertence ao imaginário lobatiano, - mas também porque tais metáforas provêm do espaço originário do próprio autor. Refiro-me, é claro, ao meio rural, isto é, àquelas "cidades mortas", ou ao Vale do Paraíba que, numa crônica de 1943, aparece como um "diamante a lapidar" (LOBATO, 1961e, p. 225), mas que, nas cartas a Godofredo Rangel, depois incluídas em A Barca de Gleyre (1961b), conformavam um espaço bem pouco glamouroso, tendo em vista o ideal civilizatório sobre o qual Lobato tinha poucas dúvidas.

Nesse espaço rural em que Monteiro Lobato foi proprietário e administrador de uma fazenda que ele depois venderia e abandonaria, se "gestam coisas", como diz ao amigo Rangel, numa carta de outubro de 1914:

Quantos elementos cá na roça encontro para uma arte nova! Quantos filões! E muito naturalmente eu gesto coisas, ou deixo que se gestem dentro de mim num processo inconsciente, que é o melhor: gesto uma obra literária, Rangel, que, realizada, será algo nuevo neste país vítima duma coisa: entre os olhos dos brasileiros cultos e as coisas da terra há um maldito prisma que desnatura as realidades. [...] Não sei como vai ser essa obra. Talvez romance. Talvez uma série de contos e coisas com uma idéia central. Nessa obra aparecerá o caboclo como o piolho da serra, tão espontâneo, tão bem adaptado como nas galinhas o piolho-de-galinha, ou como no pombo o piolho-de-pombo [...] O caboclo, piolhode-serra, também é incapaz de outra piollhagem que não a da serra. [...] Atualmente estou em luta contra quatro piolhos desta ordem - "agregados" aqui das terras. Persigo-os, quero ver se os estalo nas unhas. [...] Estudo-os. (LOBATO, 1961b, pp. 362-363, vol. 1). 
|68|

Entre duas preguiças: Macunaíma e o Jeca Tatu

Gestava-se, é claro, seu personagem Jeca Tatu, sobejamente conhecido por sua importância na história da literatura (conquanto Lobato seja amiúde vítima de um injusto apequenamento na historiografia literária brasileira), mas também por haver se tornado um arquétipo do homem rural preguiçoso.

Não é preciso ir longe: basta averiguar o quanto, no século passado, o discurso sobre a resistência do homem do campo à civilização e à tecnologia terá informado a moderna cartilha da extensão rural, na contramão da idealização romântica do sertanejo (CAROLA, 2004). Como se o agrônomo tivesse sempre que enfrentar, com as pílulas da tecnologia, um renitente Jeca Tatu, o que sugere a atualidade do embate entre a "questão agrícola", com suas poderosas soluções técnicas, e a "questão agrária", com sua urgência social (LOURENÇO, 2001). Sem esquecer, ainda, que o discurso lobatiano compreende-se no quadro mais amplo de uma reação à "decadência" que assombrava o Vale do Paraíba desde o século XIX, quando o Oeste paulista começou a prosperar (SILVA, 2012; STEIN, 1990).

Assim, pode-se supor que Jeca Tatu seja o resultado da reação a certa idealização do homem do campo, cuja raiz aponta para as projeções idílicas do espaço natural, seja na chave parnasiana, seja na vertigem romântica com a paisagem. ${ }^{1} \mathrm{O}$ trecho famoso da crônica em que nasce o Jeca Tatu, identificado a uma "praga" da civilização, se parece notavelmente a algumas das melhores páginas de Euclides da Cunha, de quem Lobato é admirador confesso. ${ }^{2}$

A queixa sobre a criatura atrasada reedita uma velha preocupação ilustrada com a técnica rudimentar da coivara, isto é, a queima do mato antes do plantio, processo que termina

\footnotetext{
2 "Esboroou-se o balsâmico indianismo de Alencar ao advento dos Rondons que, ao invés de imaginarem índios num gabinete, com reminiscências de Chateaubriand na cabeça e a Iracema aberta sobre os joelhos, metem-se a palmilhar sertões de Winchester em punho." (LOBATO, 1961d, p. 277)

2 Sobre Lobato e Euclides, consultar A Barca de Gleyre (1961b), em especial a correspondência de setembro de 1911.
} 
por exaurir o solo rapidamente, levando ao abandono sucessivo extensas áreas de cultivo, o que retomava, como se sabe, a prática de uma agricultura itinerante característica de povos indígenas:

Este funesto parasita da terra é o CABOCLO, espécie de homem baldio, semi-nômade, inadaptável à civilização, mas que vive à beira dela na penumbra das zonas fronteiriças. À medida que o progresso vem chegando com a via férrea, o italiano, o arado, a valorização da propriedade, vai ele refugindo em silêncio, com o seu cachorro, o seu pilão, a picapau e o isqueiro, de modo a sempre conservar-se fronteiriço, mudo e sorna. Encoscorado numa rotina de pedra, recua para não adaptar-se. (LOBATO, 1961d, pp. 271-272).

Como sugeriria mais tarde Antonio Candido de Mello Souza (1971, p. 46), o caipira era um "bandeirante atrofiado". Ou então, como sugerira já Euclides da Cunha, a natureza não era apenas o cenário de fundo da aventura civilizacional, mas parte integrante dela.

O homem se adapta e se embrenha no meio: afastado da cidade, exorbitando do círculo civilizacional, ele se encolhe e recua, como que adentrando um espaço e um tempo pregressos. Porém, em Euclides havia a promessa de uma força telúrica que só o sertanejo guardava, ao projetar-se como uma espécie híbrida de Hércules e Quasímodo, que manteria, na complicação genealógica que infernizava a mente do autor de Os Sertões, a potência da raça (CUNHA, 2001). Já em Lobato, o sino da civilização badala desimpedido, e o danado do Jeca é apenas uma criatura incômoda, verdadeira praga que, desgraçando a terra, abandona-a e se desloca para um pouco além, em eterna errância. Na perspectiva lobatiana, não há a promessa de uma raça que se guarda inteira, protegendose do confuso influxo genético do litoral, da mestiçagem que seria tema privilegiado de outros autores, que construiriam outras paisagens mentais, no contexto ensaístico robustecido pelo modernismo. 
Entretanto, o choque da civilização não atinge, no retrato lobatiano do sertão, os tons épicos de Euclides da Cunha. Ainda assim, a solução poética de tal choque pode ser literariamente muito significativa. Oblivion, no conto "Os perturbadores do silêncio", escrito em 1908 e posteriormente publicado em Cidades Mortas (1919), é o povoado imaginário que se congela num silêncio ártico, "inteiriço como a escuridão" (LOBATO, 1961c, p. 15). No máximo, alguns tímidos e monótonos sons quebram o silêncio durante o dia (a capina trimensal das ruas, o sino da Igreja, o fim das aulas), mas logo ele, o abarcador Silêncio, "subjuga e absorve" o som intruso, numa entropia sonora a figurar um espaço onde o avanço civilizatório é força inimiga, insidiosa e impotente.

Há em Oblivion (um nome de ressonâncias claras) um único momento em que o som inimigo parece cortar o silêncio: é quando Isaac Fac-Totum, um mulato retaco, recebe ordem de atacar um olheiro de saúvas, e mete no velho e enferrujado carrinho da Câmara as garrafas de formicida, a enxada e o fósforo. A cena de Isaac a atravessar a cidadezinha é formidável. As moças, nervosas, deixam a costura e tapam os ouvidos, enquanto as crianças se excitam. "Não obstante", conta Lobato,

[...] o terrível veículo passa, indiferente à admiração como à censura, garboso, todo de ferro e ferrugem, nhem-nhim, nhem-nhim, empurrado pela dignidade infinita de Isaac-Toco-de-Vela. Enquanto o carrinho da Câmara não torna ao depósito municipal, o Silêncio não reentra na posse dos seus domínios." (LOBATO, 1961c, p. 17).

Mas que domínios são esses? A passagem é ainda pouco clara, porque os vetores da civilização e do atraso não se definiram completamente, embora seja possível sugerir que, em 1908, Lobato já estivesse totalmente intrigado com aquela pasmaceira do ambiente rural e provinciano, capaz de absorver qualquer movimento e ruído, como que fechando o espaço aberto pelo carro num sem-tempo imóvel. Porém, aquilo que, em certa vertente da imaginação literária latino-americana, apresentar-se-ia mais tarde 
como abertura para o tempo mitopoético de um outro fantasmal e querido (que se pense no silêncio dos espaços remotos em Juan Rulfo, ou mesmo em García Márquez), em Monteiro Lobato, ao contrário, é a revelação de um espaço estático a ser rasgado pelo agente civilizador.

Mas onde buscar a agência civilizadora, a seta que deve marcar o sentido do avanço? A resposta lobatiana é clara: na "América".

De sua viagem aos Estados Unidos, entre 1927 e 1931, Lobato retira, como em tudo o mais, notável resultado literário e político. Em América, publicado em 1932, reedita-se o antigo gênero dos diálogos filosóficos, agora tendo como interlocutores o próprio Lobato viajante e, de outro lado, um imaginário Mr. Slang, personagem que já aparecera em livro anterior como um "inglês da Tijuca".

O que o impressiona é a sociedade alavancada pelos dólares americanos, a qual, mesmo após a Grande Depressão, se reerguia econômica e moralmente com o New Deal. ${ }^{3}$ Em tal sociedade, sugere Lobato,

Os dólares não existiam empilhados à flor da terra. Foram criados. Foram ganhos. A riqueza nacional americana, hoje orçada em 400 bilhões de dólares, partiu dum zero inicial. Quando o "Mayflower" aportou às costas de New England e aqueles auto-

\footnotetext{
${ }^{3}$ Enamorado das universidades americanas, Lobato visita o campus idílico de Princeton, onde os jardins pareciam tão perfeitos que se diria "que os anõezinhos do Reno vinham a noite tosar aquelas gramas e desempoeirar uma por uma as folhas das árvores" (LOBATO, 1961a, p. 81-82). Não resisto a levantar a cabeça com sarcasmo ao escrever estas linhas, porque o que Lobato viu é o resultado do mesmo trabalho invisível que mantém limpos os corredores e asseados os banheiros hoje em dia em Princeton. Trabalho noturno, invisível e estrangeiro. Só que os anõezinhos não vêm mais do Reno, mas do México e da América Central, sobretudo. Há sentido neste comentário algo maldoso: é do trabalho, justamente, que fala Lobato, embora sua visão do capitalismo não conheça grandes perturbações.
} 
exilados erigiram o primeiro casebre, a base desses 400 bilhões foi lançada. Quanto valeria esse primeiro casebre em dinheiro inglês da época? Uma libra, se tanto. Tudo veio daí. A partir daquele momento o americano jamais deixou de acumular trabalho. Riqueza é trabalho acumulado. Em vez da águia eu poria como símbolo da América a formiga. A águia depreda. A formiga enceleira. (LOBATO, 1961a, p. 83-84).

Há todo um veio a explorar quanto ao espaço da formiga na imaginação literária de Monteiro Lobato e de Mário de Andrade (bastaria recordar o dístico parodiando Saint-Hilaire, que Macunaíma vive a repetir: "pouca saúde e muita saúva, os males do Brasil são", ou a evidente referência à fábula de Esopo, no caso de Lobato). Aqui, contudo, evoco Mário de Andrade para compreender o que pode contrapô-lo a Lobato, e como o contraste entre Jeca Tatu e Macunaíma pode ser iluminador: ambos preguiçosos, situados à margem do círculo civilizacional, embora cada um ofereça uma resposta cifrada e distinta ao empuxo do progresso.

Abstenho-me de retraçar aqui as já um pouco batidas desavenças entre Lobato e os modernistas. A relação entre eles é mais interessante do que faz crer certo viés da crítica contemporânea, que herdou (ou inventou) uma espécie de urticária diante do autor de Urupês. Impõe-se questão mais simples, porventura mais interessante: como a preguiça pôde converter-se, de sinal inequívoco do atraso, em Monteiro Lobato, em potência fundadora, no Macunaíma de Mário de Andrade?

Inicialmente, é preciso recordar a gênese da escrita de Macunaima, que se desenha bem ao gosto modernista: a primeira versão da rapsódia se escreve em seis dias, numa chácara em Araraquara, "entre cigarros e rede", o que inaugura um tópos literário e pictórico que conecta Mário de Andrade a Gilberto Freyre: ambos esparramados numa rede, "criando"...

Nessa rede em que se deitam o pernambucano Gilberto Freyre e o paulista Mário de Andrade, e depois, na soberania do seu 
canto, o baiano Dorival Caymmi, "criar" é uma espécie de "verbo intransitivo", capaz de mergulhar o artista na atemporalidade que, ao contrário de Lobato, aponta para uma produtividade insuspeitada, telúrica e mítica. Toca-se aí o solo da imaginação modernista, na encruzilhada que separa Lobato de Mário.

Neste último, o prazer da escrita anuncia o jogo metalinguístico que dá a Macunaíma a graça e a agilidade que quase todos os leitores reconhecem no livro. Mas, além disso, o prazer da escrita sugere que a própria criação, ao contrário do que acontecia com a riqueza em Lobato, está justamente "empilhada à flor da terra", como que à espera do poeta que venha alegremente juntar tudo, numa cantiga tão simples quanto tocante. Como se o material poético fosse ofertado livremente ao rapsodo, que é o cantor das riquezas já existentes, desconfiado da azáfama do progresso, contrário à corrida ininterrupta da civilização moderna. De fato, o rapsodo que canta a saga do herói de nossa gente se entrega à manha circular e oralizada do mito, recusando o sentido que o discurso logocêntrico do progresso reclama e promove. Macunaíma dança, vai e vem, regressa e perde a riqueza em sua viagem perdulária de herói mítico. Como no caso de Lobato, a perda é notável, mas a diferença entre os dois não poderia ser mais clara: em Mário, a preguiça apresenta um saldo estranhamente positivo.

Não por acaso, parte importante da crítica sobre Macunaíma debate a interpretação clássica de Gilda de Mello e Souza, que vê na bricolagem de Mário de Andrade a composição de um foco narrativo onde se poderia detectar, bem lá no fundo, a voz do cantador. O tema é vasto e não cabe aqui. Basta lembrar, entretanto, que o estatuto da arte em Mário de Andrade se liga a uma concepção simpática ao popular, mas também crente na sua transcendência, como se aquele espaço retroativo do meio rural - aquele escurão danado de que Lobato foge - fosse exatamente 
o terreno sagrado em que se busca a solução poética, e talvez política, do país. ${ }^{4}$ Buscando uma fórmula simplificada, poderíamos supor que o objeto que atemoriza Lobato fascina Mário.

O autor de Macunaíma se deteve, tanto quanto o autor de América, sobre a política, na forja sempre difícil e urgente do projeto nacional. No entanto, a promessa civilizadora encampada por Monteiro Lobato é aquela diante da qual Mário de Andrade recua. Mas, se há de fato um recuo, não é porque Mário abrace uma proposta em si regressiva. Ocorre que a dimensão nacional em Mário de Andrade se liga, um tanto tragicamente, àquilo que se perdia com o progresso material e o avanço das forças produtivas. Nos termos da nossa pobre modernidade - ou da nossa pobre concepção acadêmica da modernidade -, Mário de Andrade é o único "moderno" da dupla, exatamente por ter sido capaz de encetar toda uma aventura literária cuja referência não é o que está presente, brilhando nos olhos do escritor que almeja o futuro, mas tudo aquilo que resta como matéria poética, luzindo não no futuro, mas no passado que teima em não desaparecer de todo.

Nesse complexo jogo diacrônico, convém perceber que, para Mário de Andrade, a matéria do "passado", legitimada e recuperada pelo empenho do artista interessado, deixa de ser o empecilho que o projeto civilizador lobatiano pretende varrer do mapa. Trata-se, para Mário, de um passado paradoxalmente promissor, como se o próprio futuro estivesse no passado, em seu vir-a-ser que a modernização atropela, porque identifica, na resistência da tradição, a nódoa do atraso. Em suma, no plano de sua modernidade literária, não há, para o autor de Macunaíma, simples recomposição idílica do tempo que passou. Ao contrário, nos termos celebrados de Walter Benjamin, o rapsodo lida com as

\footnotetext{
${ }^{4}$ Trabalhei o tema recentemente, ao tentar vislumbrar o projeto político e estético marioandradino nesse constante e estranho "recuo" aos espaços ainda protegidos do vento do progresso. O tema se torna especialmente agudo quando visto por meio do diálogo ente Mário de Andrade e Sérgio Buarque de Holanda. Cf. MONTEIRO, 2012.
} 
reminiscências e a memória, diante de "um inimigo que não cessa de vencer".

Sabe-se que o esforço criador do projeto de Mário de Andrade se baseia na possibilidade de "brincar" com os signos. No caso de Macunaíma, tratava-se de brincar com o corpo das palavras e das gentes, ainda que o destino daquele que brincou irresponsavelmente com as coisas da cidade termine sendo, quando se retorna ao escuro do mato virgem, o despedaçamento e a cintilação. Mas Macunaíma não vira estrela para brilhar como norte. Ele vira estrela por causa de sua incapacidade preguiçosa de fundar a civilização, o que nos põe diante de um imenso problema, quando se trata de compreender as diferenças entre Mário de Andrade e Monteiro Lobato.

Em Mário, afinal, a própria criação revela-se uma espécie de ato falho fundador, quando a voz despreocupada do rapsodo deixa escapar o que estava represado na memória - do povo, porventura - e que ninguém sabia que lá estava, faiscando. ${ }^{5}$ O imbróglio está em imaginar um projeto nacional, e com ele toda uma postura diante da política, que se fundaria no recuo diante da máquina do progresso, que é também uma máquina discursiva. Mas, estatelado numa rede, pode o criador erguer a civilização?

“Ai, que preguiça!" é um bordão facilmente alegorizável, que se torna simpático no carnaval nosso de cada dia. $\mathrm{O}$ dado trágico e inescapável é que, com o recuo diante da presença avassaladora da cidade e do "progresso", não resta nada, a não ser uma história bonita para se contar. As perguntas se impõem, em

${ }^{5}$ A ideia do acesso privilegiado à memória serve a compreender as observações de Mário, para quem o "desraçado" Aleijadinho "lembra tudo": "Evoca os primitivos itálicos, bosqueja a Renascença, se afunda no gótico, quasi francês por vezes, muito germânico quasi sempre, espanhol no realismo místico. Uma enorme irregularidade vagamunda, que seria diletante mesmo, si não fosse a força de convicção impressa nas suas obras imortais. É um mestiço, mais que um nacional. Só é brasileiro porque, meu Deus! aconteceu no Brasil. E só é o Aleijadinho na riqueza itinerante das suas idiossincrasias. E nisto em principal é que ele profetizava americanamente o Brasil..." (ANDRADE, 1984, p. 42). 
cascata: a sociedade pode avançar quando voltam-se os ouvidos completamente para a narrativa do que passou? A coletividade progride quando toda a atenção recai sobre a história que celebra a resistência da comunidade? Mas a resistência não perpetua exatamente as raízes que o avanço modernizador quer cortar, por julgá-las retrógradas, quando não apodrecidas?

Vimos que o silêncio de Oblivion, na crônica de Lobato, era a figuração de um tempo pregresso que cabia varrer vigorosamente. Mas e se, diante da tarefa civilizadora, exclamarmos "Ai, que preguiça!"? Que lógica outra se instaura, a partir desse momento? Que jogo civilizacional se inaugura com o prazer? Poderíamos imaginar a civilização como um jogo de "brincadeiras", espécie de pelada cuja "singularidade lúdica" não obedece a princípio finalista algum, a meta nenhuma?

Ao revisitar o drama brasileiro à luz dos enigmas civilizacionais atualizados pelo futebol, José Miguel Wisnik (2008, p. 272) aproxima Garrincha, "sonso, enganosamente retardado e precoce, imprevisivelmente ligado e desligado do jogo, dono de um drible que podia ser tanto a solução quanto a perdição por excesso", de Macunaíma. Nos dois casos, trata-se de um "bobo sabido", que nunca adivinharemos se apenas se faz de bobo, ou se o é, de fato. Sua força, aliás, está nessa imprevisibilidade, na maneira como ele consegue blindar seu espaço contra a lógica produtivista que só admite conclusões claras e gols certos.

Macunaíma-Garrincha é a ambivalência em sua forma mais pura: a produtividade que jamais extravasa o instante, recusando alegremente o plano chato do progresso. Mas não se trata apenas de recusar um modelo civilizacional; trata-se, como sugere Renata Wasserman (1984), da recusa da própria escolha, e do recuo diante do esforço pressuposto na escolha e na perseverança. A impotência de Macunaíma não o torna uma "figura de atualidades, mas uma fantasia de possibilidade, uma forma imaginativa de rearranjar o mundo" (WASSERMAN, 1984, p. 108; 113). Hoje talvez emprestássemos, ao herói de nossa gente, a pecha de virtual: por meio dele, descerra-se o espaço que precede a atualização, e que nos lança vertiginosamente naquele tempo em que a realidade 
confina com a imaginação. No entanto, dando voz à argúcia alerta de Lobato, convém recordar que nada se concretiza no ato mesmo de imaginar. Imaginar é no máximo uma potência propulsiva, mas fazer é arte de outra ordem, que exige a disciplina mínima que, por razões diversas, falta tanto a Macunaíma quanto a Jeca Tatu.

O potencial dessa recusa diante da pressa produtivista é conhecido na história da filosofia. Poderíamos pensar no valor do ócio para a política clássica, por exemplo. Ou então, uma preguiçosa linhagem macunaímica aponta também para o moderno "direito à preguiça" defendido pelo genro de Karl Marx, Paul Lafargue, até chegar, como sugere Edgardo Dieleke (2007), no Bartleby de Melville, aquele que, a cada instância do trabalho, respondia serenamente: "I would prefer not to...".

$\mathrm{O}$ que resta dessa cadeia de recusas (I would prefer not to..., Ai que preguiça!) é poética e politicamente poderoso, embora a pergunta sobre o avanço civilizador permaneça. Afinal, Oblivion não é apenas um lugar poético; é também o espaço real dos que foram esquecidos pelo progresso. Convenhamos que, quando se trata de fazer avançar o carro da civilização, talvez a solução de Lobato seja mais feliz: deixar-se arrastar pelas forças do progresso, encontrando um lugar ao sol naquilo que chamamos, um tanto rapidamente, de "moderno".

Mas e se Walter Benjamin estava certo quando se referiu ao quadro de Paul Klee? E se o progresso deixa atrás de si um amontoado de ruínas que cresce até o céu? Entre Mário de Andrade e Monteiro Lobato, o vento do progresso é a matéria semovente de discussão. Mas não apenas o vento em si. O que ele deixa para trás é o que realmente importa, afinal esse é ponto em que os dois autores divergem.

Uma posição consequente sugere cautela e cuidado, antes de apostar em um ou em outro. Afinal, se de crítica realmente se trata, há que lembrar que apenas na encruzilhada vive o pensamento. Ao recusar as soluções fáceis e enganosas que o caminho do "progresso" promete não precisamos nos entregar, sem mais, ao encanto da cantiga modernista ("modernista" no sentido que o termo ganhou com o modernismo de Mário e Oswald, está 
claro). Mas haveria uma terceira margem da civilização, onde a produtividade não dependa da aniquilação da preguiça? Onde a produção seja gozo e suor num único tempo? Onde Macunaíma se descobriria um operoso agricultor?

Sabemos que não, que a preguiça macunaímica é incontornável e profunda. Sabemos também que o dilema sugerido pelo embate entre Monteiro Lobato e Mário de Andrade é de todos os povos tocados pelo vento do progresso, imersos na aceleração que obriga a pensar no que está sendo deixado para trás, e por quê. Curiosamente, nos dois casos estremece-se diante do futuro, mas o pensamento, com seus matizes e dilemas próprios, segue impulsionado pelas ruínas. Esquecê-las ou lembrá-las, aboli-las ou reverenciá-las, eis o dilema e a questão. ${ }^{6}$

\section{Bibliografia}

ANDRADE, Mário de. Aspectos das artes plásticas no Brasil. Belo Horizonte: Itatiaia, 1984.

Macunaíma. Madrid, Paris, México, Buenos Aires, São Paulo, Rio de Janeiro, Lima: ALLCA XX, 1996 [1928].

BENJAMIN, Walter. Magia e técnica, arte e política: ensaios sobre literatura e história da cultura. Trad. Sergio Paulo Rouanet. São Paulo: Brasiliense, 1985.

CAROLA, Carlos Renato. “Jeca Tatu e o processo civilizador da família rural brasileira". 80 Simpósio Processo Civilizador, História e Educação: novas exigências do processo civilizador

na contemporaneidade. João Pessoa: Universidade Federal da Paraíba, 2004.

CUNHA, Euclides da. Os Sertões (Campanha de Canudos). Ed. Leopoldo M. Bernucci. São Paulo: Ateliê Editorial, Imprensa Oficial do Estado, Arquivo do Estado, 2001. 
DIELEKE, Edgardo. "Genealogies and Inquiries into Laziness from 'Macunaíma'" ellipsis: The Journal of the American Portuguese Studies Association, vol. 5, 2007, pp. 9-24.

IVO, Lêdo. A ética da aventura. Rio de Janeiro: Francisco Alves, 1982.

LAJOLO, Marisa. "Linguagens na e da literatura infantil de Monteiro Lobato". In: LAJOLO, Marisa; CECCANTINI, João Luís (orgs.). Monteiro Lobato, livro a livro: Obra Infantil. São Paulo: Editora UNESP, Imprensa Oficial do Estado, 2008, pp. 15- 29.

LOBATO, José Bento Monteiro. América. São Paulo: Brasiliense, 1961a [1931]. A barca de Gleyre. São Paulo: Brasiliense, 1961b, 2 vols. [1944].

. Cidades mortas. São Paulo: Brasiliense, 1961c [1919].

. Urupês. São Paulo: Brasiliense, 1961d [1918].

. Idéias de Jeca Tatu. São Paulo: Brasiliense, 1961e. [1919].

LOURENÇO, Fernando Antonio. Agricultura ilustrada: liberalismo e escravismo nas origens da questão agrária brasileira. Campinas, Editora da Unicamp, 2001.

MONTEIRO, Pedro Meira. “Coisas sutis, ergo profundas: o diálogo entre Mário de Andrade e Sérgio Buarque de Holanda". In: MONTEIRO, Pedro Meira (org.). Mário de Andrade e Sérgio Buarque de Holanda: Correspondência. São Paulo: Companhia das Letras, EdUSP, Instituto de Estudos Brasileiros da USP, 2012, pp. 169-360.

MORAES, Marcos Antonio de (ed.). Correspondência Mário de Andrade \& Manuel Bandeira. São Paulo: EdUSP, 2001.

SANTIAGO, Silviano (ed.). Carlos \& Mário: correspondência de Carlos Drummond de Andrade e Mário de Andrade. Rio de Janeiro: Bem-te-vi, 1998. 
SILVA, Luciana Meire da. “Cidades Mortas: o declínio da 'civilização cafeeira' no Vale do Paraíba segundo a elite agrária decadente". Idéias, Revista do Instituto de Filosofia e Ciências Humanas, Unicamp, vol. 1, n. 4, 2012, pp. 289-305.

SOUZA, Antonio Candido de Mello e. Os parceiros do Rio Bonito: estudo sobre os caipiras paulistas e a transformação dos seus meios de vida. São Paulo: Livraria Duas Cidades, 1971.

SOUZA, Gilda de Mello e. O tupi e o alaúde. São Paulo: Duas Cidades, Editora 34, 2003.

STEIN, Stanley J. Vassouras: um município brasileiro do café, 1850-1900. Trad. Vera Bloch Wrobel. Rio de Janeiro: Nova Fronteira, 1990.

WASSERMAN, Renata R. Mautner. "Preguiça and Power: Mário de Andrade's Macunaíma". Luso-Brazilian Review, vol. 21 n. 1, 1984, p. 99-116.

WISNIK, José Miguel. Veneno remédio: o futebol e o Brasil. São Paulo: Companhia das Letras, 2008. 